The INL is a

U.S. Department of Energy

National Laboratory

operated by

Battelle Energy Alliance

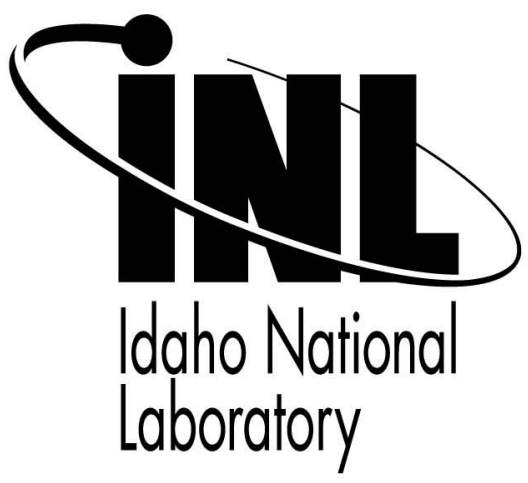

INL/CON-08-14135

PREPRINT

\section{Fission Product Monitoring of TRISO Coated Fuel for the Advanced Gas Reactor-1 Experiment}

\section{$4^{\text {th }}$ International Topical Meeting on High Temperature Reactor Technology}

\author{
Dawn M. Scates \\ John K. Hartwell \\ John B. Walter \\ Mark W. Drigert \\ Jason M. Harp
}

\section{September 2008}

This is a preprint of a paper intended for publication in a journal or proceedings. Since changes may be made before publication, this preprint should not be cited or reproduced without permission of the author. This document was prepared as an account of work sponsored by an agency of the United States Government. Neither the United States Government nor any agency thereof, or any of their employees, makes any warranty, expressed or implied, or assumes any legal liability or responsibility for any third party's use, or the results of such use, of any information, apparatus, product or process disclosed in this report, or represents that its use by such third party would not infringe privately owned rights. The views expressed in this paper are not necessarily those of the United States Government or the sponsoring agency. 


\section{FISSION PRODUCT MONITORING OF TRISO COATED FUEL FOR THE ADVANCED GAS REACTOR-1 EXPERIMENT}

\author{
Dawn M. Scates \\ Idaho National \\ Laboratory \\ Idaho Falls, ID, USA
}

\author{
John K. Hartwell \\ Idaho National \\ Laboratory \\ Idaho Falls, ID, USA
}

\author{
John B. Walter \\ Idaho National \\ Laboratory \\ Idaho Falls, ID, USA
}

\author{
Mark W. Drigert \\ Idaho National \\ Laboratory \\ Idaho Falls, ID, USA
}

\author{
Jason M. Harp \\ North Carolina State \\ University \\ Raleigh, NC, USA
}

\section{ABSTRACT}

The US Department of Energy has embarked on a series of tests of TRISO-coated particle reactor fuel intended for use in the Very High Temperature Reactor (VHTR) as part of the Advanced Gas Reactor (AGR) program. The AGR-1 TRISO fuel experiment, currently underway, is the first in a series of eight fuel tests planned for irradiation in the Advanced Test Reactor (ATR) located at the Idaho National Laboratory (INL). The AGR-1 experiment reached a peak compact averaged burn up of 9\% FIMA with no known TRISO fuel particle failures in March 2008. The burnup goal for the majority of the fuel compacts is to have a compact averaged burnup greater than $18 \%$ FIMA and a minimum compact averaged burnup of $14 \%$ FIMA.

At the INL the TRISO fuel in the AGR-1 experiment is closely monitored while it is being irradiated in the ATR. The effluent monitoring system used for the AGR-1 fuel is the Fission Product Monitoring System (FPMS). The FPMS is a valuable tool that provides near real-time data indicative of the AGR-1 test fuel performance and incorporates both highpurity germanium (HPGe) gamma-ray spectrometers and sodium iodide $[\mathrm{NaI}(\mathrm{Tl})]$ scintillation detector-based gross radiation monitors.

To quantify the fuel performance, release-to-birth ratios (R/B's) of radioactive fission gases are computed. The gamma-ray spectra acquired by the AGR-1 FPMS are analyzed and used to determine the released activities of specific fission gases, while a dedicated detector provides near-real time count rate information. Isotopic build up and depletion calculations provide the associated isotopic birth rates. This paper highlights the features of the FPMS, encompassing the equipment, methods and measures that enable the calculation of the release-to-birth ratios. Some preliminary results from the AGR-1 experiment are also presented.

\section{INTRODUCTION}

The US Department of Energy has embarked on a series of tests of TRISO-coated particle reactor fuel intended for use in the Very High Temperature Reactor (VHTR) as part of the Advanced Gas Reactor (AGR) program [1]. The AGR-1 experiment, currently in progress, is the first in a series of fuel irradiations in the Advanced Test Reactor (ATR). One important measure of the fuel performance in these tests is quantification of the fission gas releases over the duration of each irradiation experiment. This important measurement is provided by the AGR Fission Product Monitoring System (FPMS) $[2,3]$.

The AGR-1 experiment reached full power on December 26, 2006 and in March of 2008 reached a peak compact averaged burn up of 9\% FIMA (Fissions per Initial Metal Atom.) The burnup goal for the majority of the fuel compacts is to have a compact averaged burnup greater than $18 \%$ FIMA and a minimum compact averaged burnup of 14\% FIMA [4]. AGR-1 is what is termed an "instrumented lead" experiment. The fueled section of the test train that is inserted into the ATR irradiation port connects through an umbilical cord (termed a lead-out) to systems outside the reactor vessel. The AGR-1 test train incorporates six (6) individual test capsules [5]. Each capsule contains about 51,000 TRISO (TRIstructural ISOtropic) coated fuel particles supported in a graphite matrix. Each capsule is instrumented with thermocouples and is continuously swept with an inert gas during irradiation. The effluent gas from each capsule is independently monitored by the FPMS in near real time. The primary functions of this system are to detect the fission gas release that occurs when a TRISO fuel coating may have failed, and to provide the data to support release-to-birth ratio $(\mathrm{R} / \mathrm{B})$ calculations.

The FPMS consists of seven (7) fission product monitor stations, one for each capsule plus a spare. Each station consists of a heavily-shielded high-purity germanium (HPGe) 
gamma-ray spectrometer for determining specific fission gas release concentrations and a sodium iodide [NaI(Tl)] scintillation detector for count rate monitoring of the capsule effluent. The scintillation detector, also referred to as the "gross radiation" monitor, provides indication when a "puff" release occurs that is indicative of a TRISO coating failure. A simplified graphic of the AGR-1 gas flow path is presented in Figure 1.

Release-to-birth ratios $(\mathrm{R} / \mathrm{Bs})$ of the radioactive fission gases are important fuel performance metrics [6, 7]. The gamma-ray spectra acquired on the AGR-1 capsule effluents by the AGR FPMS are analyzed to elucidate the activity concentrations of important fission gases at the monitoring station locations. The $\mathrm{R} / \mathrm{B}$ ratio is the ratio of the release rate (atoms/second) to the birth rate (atoms/second) of the isotope in the fuel. In addition, several different semi-empirical models have been developed that predict the $\mathrm{R} / \mathrm{B}$ behavior of TRISO fuel. The equipment, methods and measurements that enable these $\mathrm{R} / \mathrm{B}$ calculations and some preliminary result from the AGR-1 experiment are presented in this paper.

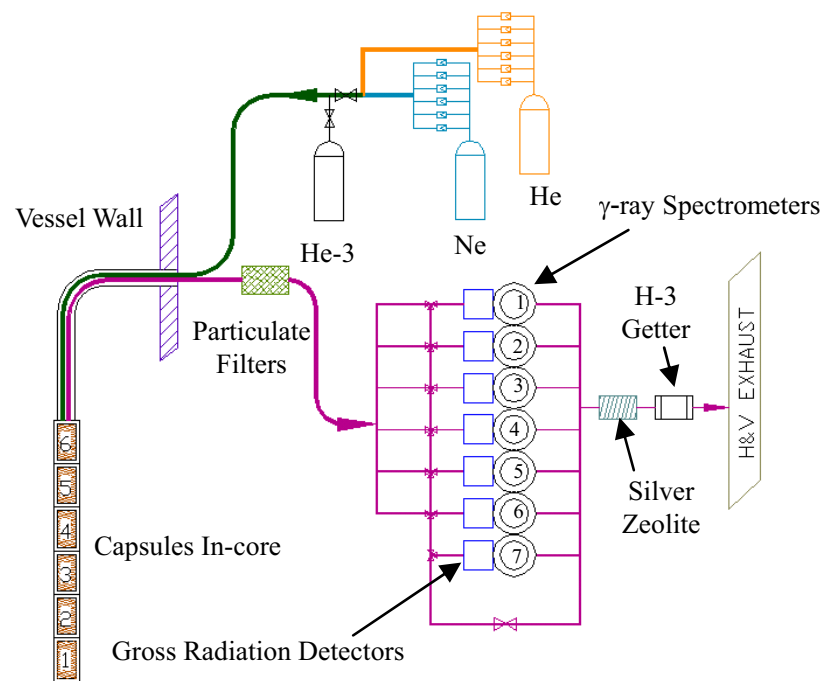

FIGURE 1: Simplified gas flow path for the AGR-1 experiment.

\section{EQUIPMENT AND METHODS}

\section{THE FPMS DESIGN, INSTALLATION AND CALIBRATION}

Each fuel test capsule is continuously swept with an inert gas during irradiation. Each capsule effluent line (there are six) exits the reactor vessel through an experiment flange, routes the gas through a particulate filter (primarily for protection against irradiated particles downstream), and then enters into a shielded "cubicle" in the ATR basement where the FPMS monitoring stations are installed. The effluent lines are contained in a shielded pipe chase channel as they run along the cubicle wall until they reach the location of their associated monitoring station. Each sample line then leaves the pipe chase channel, passes through the associated gross radiation monitor, and then into the HPGe spectrometer shield where the effluent flows through a baffled $58 \pm 3 \mathrm{~cm}^{3}$ sample chamber enclosed in a beaker located at the center bottom of each shield. The sample chamber is viewed by the HPGe detector from below through a collimator. Collimators with circular aperture diameters of $38.1 \mathrm{~mm}, 19.0 \mathrm{~mm}$, and $9.5 \mathrm{~mm}$ are available. The gamma-ray spectrometer detectors are closed-end coaxial HPGe detectors with a nominal relative efficiency of $10 \%$. The gross gamma-ray radiation monitor detectors are $\varnothing 25 \mathrm{~mm}$ X $25 \mathrm{~mm} \mathrm{NaI(Tl)}$ detectors. Specific fission gas transport times from in-core capsule to associated spectrometer have been measured. At nominal gas effluent flow rates of $0.5 \mathrm{~cm}^{3} / \mathrm{sec}$, the transport times range from $240 \pm$ 16 seconds (Capsule 5) to $276 \pm 16$ seconds (Capsule 2) [8].

Figure 2 features a photograph of the seven detector stations installed in the ATR with annotations on the foremost station. Figure 3 shows the details of the interior of the HPGe spectrometer shield, including the collimator and flow through sample chamber.

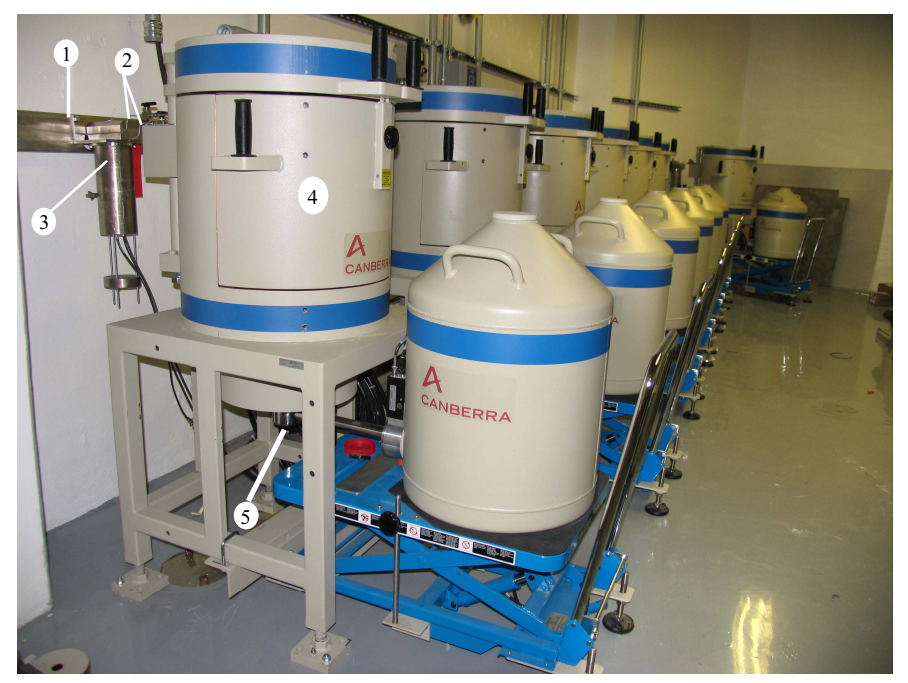

FIGURE 2: The seven FPMS detector stations installed at the Advanced Test Reactor. The pipe chase channel (1) carries the test capsule effluent lines to and from the monitoring stations. Each capsule effluent line (2) branches from the channel, passes through the gross radiation monitoring station (3) where it is viewed by a shielded NaI(TI) detector, and then into the HPGe spectrometer shield (4) and through the spectrometer sample chamber viewed by the HPGe detector (5) The effluent line returns to the pipe chase channel and leaves the cubicle to the treatment filters and then to the plant ventilation system.

Each spectrometer was calibrated using a set of simulated gas standards prepared by a source vendor in sample chambers that mimicked the FPMS flow-through chambers. The simulated gas matrix is a low density foam to which calibrated standard materials are added. Two NIST-traceable standards, one with a "mixed radionuclide source" and one 
with ${ }^{152} \mathrm{Eu}$, provided calibration points from $60 \mathrm{keV}$ to about $1800 \mathrm{keV}$. A third simulated gas sample was prepared with an uncalibrated amount of ${ }^{232} \mathrm{U}$ and daughters. The ${ }^{232} \mathrm{U}$ sample was calibrated by reference of its several lines below 1800 $\mathrm{keV}$ to the NIST-standard developed curve, and once calibrated allowed extension of the curve to $2600 \mathrm{keV}$. In this way calibration curves of efficiency as a function of gammaray energy were constructed for all detectors and collimator combinations.

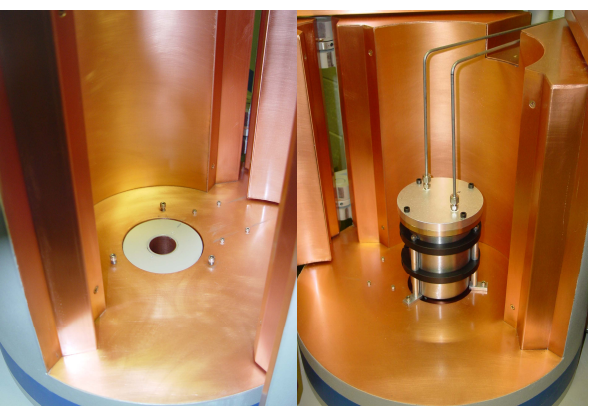

(1)

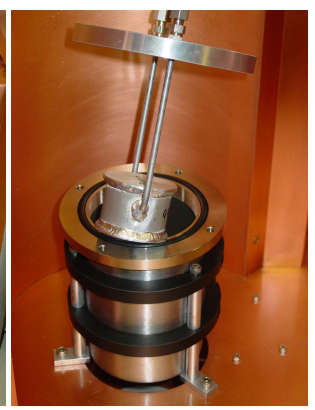

(3)
FIGURE 3: Interior of HPGe spectrometer sheild: (1) a collimator installed in the floor of an FPMS shield; (2) sample assembly fully installed over collimator; and (3) flow-through sample chamber and flow lines withdrawn from the containment beaker. The detector is up-looking with the detector face located $127 \mathbf{~ m m}$ below the inner floor of the shield.

The FPMS gamma-ray detectors have standard commercial pulse processing electronics modified to implement the INL pulse injection with subsequent removal technology[9]. This provides quality assurance data in the gamma-ray spectra that the authors believe is essential for unattended operation of the gamma-ray spectrometers. The $\mathrm{NaI}(\mathrm{Tl})$ gross detectors are equipped with multichannel scalar (MCS) units to obtain counts in successive time intervals, while the HPGe spectrometers are processed by multichannel analyzer (MCA) units to obtain counts vs. pulse height. Thus the MCS data details the time for changes in count rate, while the MCA data details the energy of the gamma rays. The MCS and MCA for each station are implemented in a Canberra Multiport II and a Canberra AIM, respectively. Both have histogramming memory and are controlled via an ethernet connection. The control software was configured with two Ethernet adapters to isolate the data acquisition modules from the INL network which provides remote access to the control computer. Acquisition control and data archival and analysis software have been developed at the INL to automate the acquisition tasks. The control software is designed to operate without continual operator intervention. It communicates with the Canberra acquisition modules through a proprietary Canberra Virtual Data Manager (VDM). This communication is accomplished using the proprietary Canberra Genie 2000 Programming Library.
The FPM control program monitors the operations of each of the seven monitoring stations (one station for each fuel capsule and one on-line live spare) continually. The operation of each station is logged to a disk file and provides a permanent record of the operation of the system over the course of the fuel irradiation. The user interacts with the control system through a graphical user interface to select which channels in the measurement system to use and what type of measurement to conduct on each system. Typically, each station is operated with the MCS and MCA in tandem, starting and stopping at the same time. The parameters for each measurement station can be set independently; however, in practice all spectrometers are usually set for the same acquisition time. The usual measurement protocol acquires gamma-ray spectra with counting times of eight hours. This acquisition period gives adequate measurement sensitivity and provides three sets of results each day. Graphical tools are implemented that allow the operator to display and review all seven HPGe spectrometers or all seven gross monitor plots at a glance and to display and investigate any individual acquiring or archived spectral files.

The control program monitors the operation of the data acquisition and at the end of the preset measurement time, saves the collected spectra to disk and initiates the online analysis task. An example spectrum is presented in Figure 4.

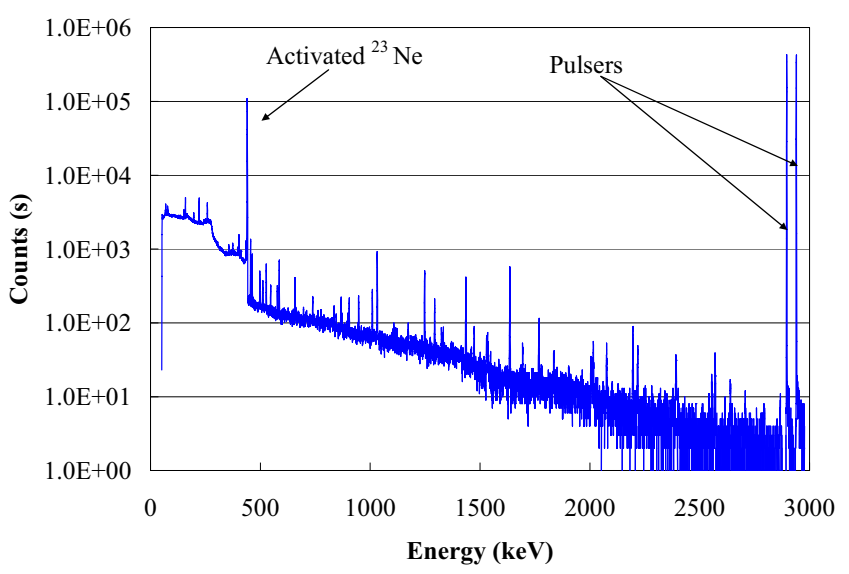

FIGURE 4: A sample spectrum of the effluent from an AGR-1 capsule. The large peak located at $439.9 \mathrm{keV}$ is from ${ }^{23} \mathrm{Ne}$ from activation of the inlet gas. The pulser peaks are the result of pulse injection with subsequent removal[9].

Acquired spectra are analyzed automatically using the INL-developed PCGAP gamma-ray spectral analysis code $[10,11]$. When the online analysis is completed, which requires a few seconds, the control program restarts the data collection phase automatically. Additionally, the control program performs incremental saves during each acquisition period. These incremental saves are "snapshots" of the acquired data at intervals preset by the operator and can be used if necessary to recreate an acquisition profile in the event of equipment failure or electronic upsets during each 
acquisition. Operators periodically review the acquired FPMS data and can choose to retain or purge the saved incremental data. The control software continues the measurement/analysis cycle until stopped by the operator.

The operation of the control software is monitored by a separate supervisory process. This process monitors the control program and if the control program becomes nonresponsive for any reason, the supervisor process halts and restarts it. On startup the control program thus resumes monitoring of any ongoing acquisition and therefore no data is lost. The supervisor process periodically reports, via electronic mail to designated personnel, the status of the control program and any problems requiring a restart of the control program. A failure in the computer that hosts the control software is reported to an ATR-based operator by an alarm activated by a network-controllable power switch attached to the host computer's private ethernet subnet. The switch monitors a CPU "heartbeat." If the heartbeat stops, the alarm activates.

In addition to saving each gamma-ray and gross monitor spectrum, analyzing the acquired spectra to determine fission gas concentrations and providing the required control and error recovery functions, a number of auxiliary programs are implemented to simplify data review and to provide data in a format that supports the calculation of release-to-birth ratios. The results of the gamma-ray spectral analyses are saved in a format accessible to a display code that allows the operator to rapidly review plots of selected fission gas nuclide activity as a function of capsule and time. An example of one of these plots from "Fission Product Examiner" is presented in Figure 5. These saved activity files form the basis for the computation of release rates.

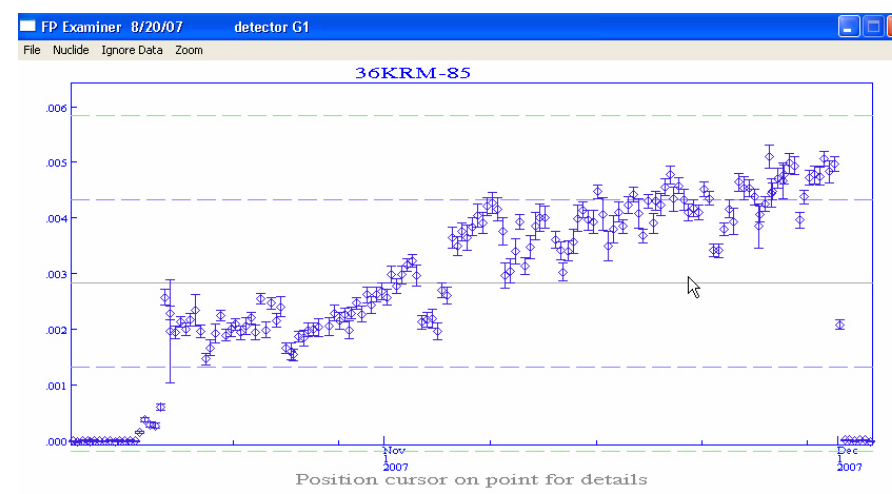

FIGURE 5: An example plot from Fission Product Examiner presents activity of ${ }^{85 \mathrm{~m}} \mathrm{Kr}$ measured at the spectrometer monitoring the effluent from AGR-1 Capsule 1 over the duration of an ATR irradiation cycle (140A, October 16, 2008 - November 30, 2008). The $y$-axis is activity in $\mu \mathrm{Ci}$ and the $\mathrm{x}$-axis is the date and time at start of the count.

\section{DATA ANALYSIS}

The most commonly applied metric for fuel integrity monitoring of TRISO fuel is the release-to-birth ratio of the fission gas nuclides [6, 7]. The FPMS measured activities are corrected to account for decay that occurs during transport from the capsules to the detectors. Transport times are calculated from outlet gas flow rates recorded by the automated experiment data acquisition system of the ATR [12] and the capsule-specific volumes through which samples flow to reach the monitoring stations. The required isotopic birth rates are computed from inventory data supplied using a code termed MCWO (for Monte Carlo With Origen) developed at the INL that links neutronic data computed in MCNP to inventory data computed in ORIGEN2 [13].

The proper correction of fission gas activities measured at a given spectrometer to the desired atom/second release rate at the capsule is calculated for equilibrium conditions, with reference to the simplified flow graphic of Figure 6.

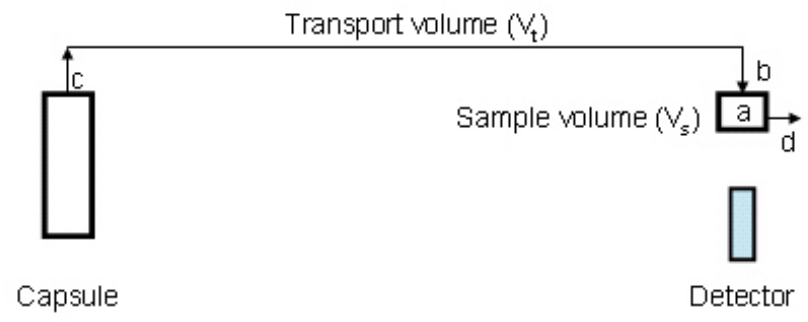

FIGURE 6: A simplified single capsule flow graphic to aid in flow correction calculations.

At equilibrium, when the rate of change of the number of atoms of nuclide $i$ in the sample volume $a$ is zero, one can derive:

$$
R_{c_{i}}=\frac{A_{a_{i}} \cdot e^{\lambda_{i} \cdot V_{t} / \dot{f}}}{\left(1-e^{-\lambda_{i} \cdot V_{s} / \dot{f}}\right)}
$$

Where: 


$$
\begin{aligned}
R_{c_{i}}= & \text { the desired atom } / \mathrm{sec} \text { release rate of } \\
& \text { nuclide } i \text { at the capsule exit }(c) \\
A_{a_{i}}= & \text { the activity }(\mathrm{Bq}) \text { of nuclide } i \text { measured in } \\
& \text { sample volume } a \\
\lambda_{\mathrm{i}}= & \text { the decay constant of nuclide } i\left(\mathrm{sec}^{-1}\right) \\
V_{t}= & \text { the transport volume }\left(\mathrm{cm}^{3}\right) \text { between }(\mathrm{c}) \\
& \text { and (b) } \\
V_{s}= & \text { the sample volume }\left(\mathrm{cm}^{3}\right)(\mathrm{a}) \\
\dot{f}= & \text { the measurement }- \text { time averaged capsule } \\
& \text { outlet flow }\left(\mathrm{cm}^{3} / \mathrm{sec}\right)
\end{aligned}
$$

The estimated uncertainty in $R_{c_{i}}$ can be determined from standard error propagation techniques to be:

$$
\sigma_{R_{c i}}^{2}=\left(\frac{R_{c i}}{A_{a_{i}}}\right)^{2} \cdot\left(\sigma_{A_{a_{i}}}^{2}\right)+\left(\frac{R_{c i} \cdot \lambda_{i}}{f}\right)^{2} \cdot\left(\sigma_{V_{t}}^{2}\right)+\left(\frac{R_{c i} \cdot e^{-\lambda_{i} V_{s}^{s} / f} \cdot \lambda_{i}}{\dot{f} \cdot\left(1-e^{-\lambda_{i} V_{s} / \hat{f}}\right)}\right)^{2} \cdot\left(\sigma_{V_{s}}^{2}\right)
$$

or in terms of relative errors:

$$
\left(\frac{\sigma_{R_{c i}}}{R_{c i}}\right)^{2}=\left(\frac{\sigma_{A_{a_{i}}}}{A_{a_{i}}}\right)^{2}+\left(\frac{\lambda_{i} \cdot V_{t}}{\dot{f}}\right)^{2}\left(\frac{\sigma_{V_{t}}}{V_{t}}\right)^{2}+\left[\frac{V_{s} \cdot e^{-\lambda_{i} V_{s}^{s} / f} \cdot \lambda_{i}}{\dot{f} \cdot\left(1-e^{-\lambda_{i} V_{s}^{s} / f}\right)}\right]^{2}\left(\frac{\sigma_{V_{s}}}{V_{s}}\right)^{2}
$$

The birth rate for an individual isotope is simply defined as the cumulative yield of a nuclide multiplied by the fission rate in the fuel. In order to calculate this value, the birth rate of nuclide $i$ is computed in ORIGEN2 [13] from a special "non-depleting" inventory. Inventories $\left(I_{i}\right)$ in atoms are computed at two different times $t_{1}$ and $t_{2}$ using a special library in which the half life of $i$ is set to infinity (stable) and the depletion cross sections for $i$ are set to zero. The birth rate of $i$ at time $t$ (which is taken as the midpoint between $t_{1}$ and $t_{2}$ ) is then given as:

$$
B_{i}(t)=\frac{I_{i}\left(t_{2}\right)-I_{i}\left(t_{1}\right)}{\left(t_{2}-t_{1}\right)}
$$

In practice, the calculation times $t_{1}$ and $t_{2}$ are generally two to ten days apart. Uncertainties for the birth rates are determined from engineering estimates of the inventory uncertainties, propagated to the difference.

The desired release-to-birth ratio for nuclide $i$ is then calculated as:

$$
\left(\frac{R}{B}\right)_{i}(t)=\frac{R_{c_{i}}(t)}{B_{i}(t)}
$$

with a relative uncertainty $\left(\% \sigma_{\mathrm{i}}\right)$ given by:

$$
\% \sigma_{i}=\sqrt{\left(\frac{\sigma_{R_{c i}}}{R_{c i}}\right)^{2}+\left(\frac{\sigma_{B_{i}}}{B_{i}}\right)^{2}} \times 100
$$

To speed the calculation of these ratios and to ensure accuracy, a semi-automatic processing code has been developed that accesses the results of each spectral analysis to extract the required results for activity at the detector at a given time, extracts from the ATR data system files the required capsule outlet flow rates, performs the release rate calculations and then correlates these with the appropriate birth rates to compute release-to-birth ratios.

\section{RESULTS AND DISCUSSION}

\section{PRELIMINARY R/B VALUES}

The gross monitoring plots and the spectrometer data acquired on AGR-1 are routinely examined for evidence of irradiation test-induced TRISO fuel particle failures. Typically a fuel particle failure would be indicated on the gross monitoring system by an observed "puff" release. By March 2008 the test fuels have exceeded peak burnups of 9\% FIMA with no evidence of a particle failure. All measured releases as indicated by the spectrometer data are assumed to come from heavy metal contamination.

This excellent fuel performance is reflected in the measured $\mathrm{R} / \mathrm{B}$ values. For example, preliminary $\mathrm{R} / \mathrm{B}$ values for ${ }^{85 \mathrm{~m}} \mathrm{Kr}$, ${ }^{88} \mathrm{Kr}$, and ${ }^{135} \mathrm{Xe}$ computed for AGR-1 Capsule 4 during ATR irradiation cycle 140A are presented in Figure 7. Note that by the end of this irradiation cycle R/Bs for ${ }^{85 \mathrm{~m}} \mathrm{Kr}$ were about $2.1 \times 10^{-8}$ and the upward trend as illustrated in Figure 7 is because of an increasing fission power and hence, fuel temperature in the experiment. Petti et al [14] summarized ${ }^{85 \mathrm{~m}} \mathrm{Kr}$ release-to-birth ratios from about 20 US and 23 German TRISO fuel irradiation experiments conducted prior to 2002. The listed experiments encompassed a wide range of test conditions and parameters. The high performance German fuel exhibited ${ }^{85 \mathrm{~m}} \mathrm{Kr} \mathrm{R} / \mathrm{Bs}$ ranging from a low of $3 \times 10^{-9}$ to a high of $1.0 \times 10^{-5}$ with a mean over all experiments and conditions of $8.0 \times 10^{-8}$. Thus, the measured ${ }^{85 \mathrm{~m}} \mathrm{Kr} \mathrm{R} / \mathrm{B}$ of $2.1 \times 10^{-8}$ places this test fuel among the best performers. 


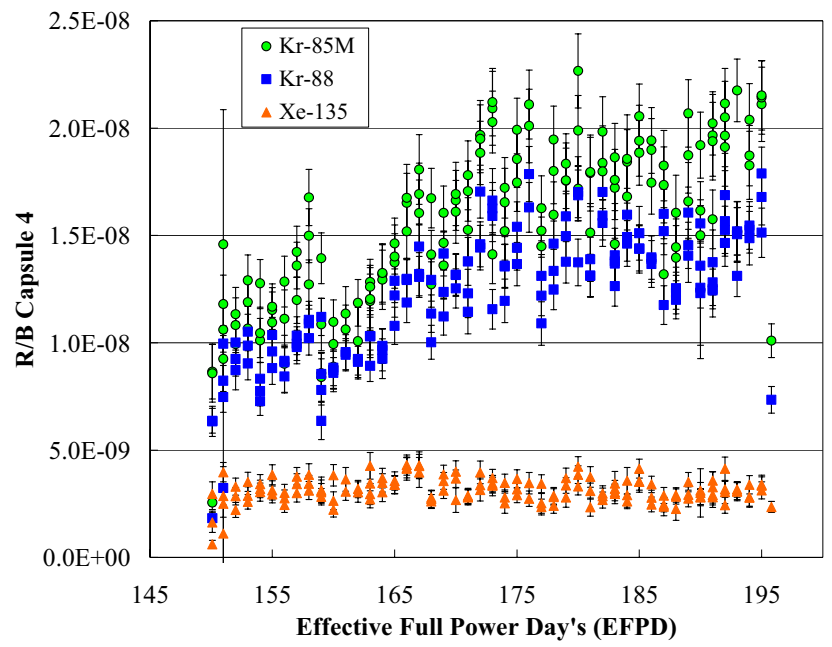

FIGURE 7: Preliminary release-to-birth ratios for ${ }^{85 \mathrm{~m}} \mathrm{Kr},{ }^{88} \mathrm{Kr}$, and ${ }^{135} \mathrm{Xe}$ computed for the test fuel in Capsule 4 during irradiation cycle $140 \mathrm{~A}$ of the AGR-1 experiment.

\section{FISSION GAS RELEASE MODELS}

The silicon carbide layer of the TRISO particle is the primary barrier to fission gas release. If this layer fails, the fission gases of $\mathrm{Kr}$ and $\mathrm{Xe}$, begin to diffuse out of the fuel kernel and into the effluent stream. Fission gas may also be ejected from the particle or compact by recoil during decay. $\mathrm{R} / \mathrm{B}$ models have been developed to model this release for both failed TRISO particles and heavy metal contamination in the fuel.

Gaseous diffusion is the main pathway of release for the noble gas fission products. The short-lived nuclides of interest quickly reach an equilibrium activity concentration in the fuel a few days into each ATR cycle. Once at equilibrium, most $\mathrm{R} / \mathrm{B}$ models describe the diffusion of the $\mathrm{Kr}$ and $\mathrm{Xe}$ gas using the Booth equivalent sphere model [15]. The general form of the Booth model is shown in the equation below.

$$
\left(\frac{R}{B}\right)=3 \sqrt{\frac{D}{\lambda a^{2}}}\left[\operatorname{coth}\left(\sqrt{\frac{\lambda a^{2}}{D}}\right)-\sqrt{\frac{D}{\lambda a^{2}}}\right]
$$

Where $\mathrm{D}$ is an effective diffusion coefficient, $a$ is the radius of the equivalent sphere, and $\lambda$ is the decay constant. Often the $\mathrm{D} / a^{2}$ terms are treated as a single empirical term in the Booth Model. In these cases, $\mathrm{D} / a^{2}$ is replaced by $\mathrm{D}^{\prime}$ and called the reduced diffusion coefficient. The key term in this model is the temperature-dependent diffusion coefficient. In some models this term is also element dependent.

Several models have been developed and investigated for their applicability to current TRISO irradiations $[16,17,18]$. This paper will compare the preliminary AGR-1 data to the model for heavy metal contamination presented in reference 7 that will be referred to as the PARFUME model. This model uses the general form of the Booth equation presented above, and the reduced diffusion coefficient $\left(\mathrm{D}^{\prime}\right)$ utilizes two different element and temperature dependent correlations.

The total $\mathrm{R} / \mathrm{B}$ value for a particular nuclide is found by multiplying the model determined $\mathrm{R} / \mathrm{B}$ by the available fraction of heavy metal originating from either failure or contamination, and then summing the contributions from the failure and contamination sources. For comparison to the experimentally measured $\mathrm{R} / \mathrm{B}$ values, the total $\mathrm{R} / \mathrm{B}$ for isotope $i$ is shown in the equation below.

$$
\left(\frac{R}{B}\right)_{i}^{\text {total }}=\mathrm{f}_{\text {fail }}\left(\frac{R}{B}\right)_{i}^{\text {fail }}+\mathrm{f}_{\text {cont }}\left(\frac{R}{B}\right)_{i}^{\text {contamination }}
$$

Where $f_{\text {fail }}$ is the fraction of failed TRISO particles, $f_{\text {cont }}$ is the contamination fraction that is defined as the grams of Uranium contamination over the grams of Uranium in the observed system, and $(\mathrm{R} / \mathrm{B})_{\mathrm{i}}$ is calculated from the model being investigated. Currently, only the contamination portion of the PARFUME model is applied because of the absence of any TRISO failures in the AGR-1 experiment.

Comparison of measured $\mathrm{R} / \mathrm{B}$ values to predicted $\mathrm{R} / \mathrm{B}$ values from the $\mathrm{R} / \mathrm{B}$ models is another metric for gauging fuel performance and the predictive capabilities of future TRISO irradiations. R/B values for ATR cycle $140 \mathrm{~B}$ of the AGR-1 experiment were calculated using the PARFUME model at a temperature of $1150^{\circ} \mathrm{C}$ and a contamination fraction of $1.26 \times 10^{-7}[19]$. Figure 8 contains a preliminary comparison of calculated $R / B$ values to an average of measured $R / B$ values taken during a portion of the $140 \mathrm{~B}$ cycle for each isotope of interest. The error bars indicate one standard deviation of the measured $\mathrm{R} / \mathrm{B}$ values.

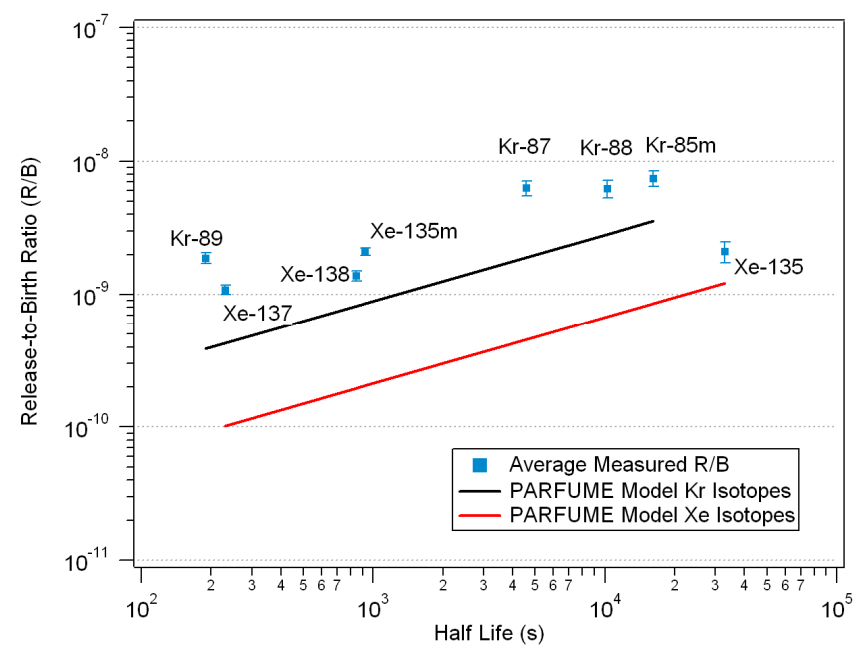

FIGURE 8: Preliminary average R/B's measured for ATR cycle 140B AGR-1 capsule 4 and model dependent $R / B$ ratios for $1150^{\circ} \mathrm{C}$ and $f_{\text {cont }}=1.26 \times 10^{-7}$. 
The difference between the model values for the $\mathrm{Kr}$ isotopes and the measured values is approximately a factor of 2. This difference can possibly be linked to a few different factors. Most notably, any error in the contamination fraction used in these calculations is directly proportional to the magnitude of the $\mathrm{R} / \mathrm{B}$ model values. Also, the reduced diffusion coefficients used in the PARFUME model are based on German fuel tests. The compact density in the German tests were $1.7 \mathrm{~g} / \mathrm{cm}^{3}$ while the compact density for the AGR-1 compacts is $1.3 \mathrm{~g} / \mathrm{cm}^{3}$ [20]. The greater open porosity might enhance diffusion. It is important to note that in Figure 8 the model value is under predicting the measured $\mathrm{R} / \mathrm{B}$ value when in most published comparisons the models over predict releases [21]. This is currently under investigation.

The form of Figure 8 is convenient for the observation of several key trends that are related to the physics of fission gas release $[18,22]$. From the Booth model it is clear that $\mathrm{R} / \mathrm{B}$ ratios are proportional to the square root of the half life. This diffusion trend gives the models and the measured data their straight line shape as a function of half life on the log log plot shown in Figure 8. In the PARFUME model, there are two separate trends for $\mathrm{Kr}$ and $\mathrm{Xe}$ release caused by different reduced diffusion coefficients $\left(\mathrm{D}^{\prime}\right)$ for $\mathrm{Kr}$ and $\mathrm{Xe}$.. Examination of the $\mathrm{R} / \mathrm{B}$ values for $\mathrm{Kr}$ isotopes and the $\mathrm{Xe}-137$ and $\mathrm{Xe}-138$ isotopes suggests that the difference in $\mathrm{Kr}$ and $\mathrm{Xe}$ behavior is not as dramatic as suggested by the model.

The comparison to model values also indicates that it is unlikely that a TRISO particle has failed. A single failed particle would correspond to a failure fraction of $1.95 \times 10^{-5}$ (roughly 1 in 50,000). According to the PARFUME model a single failed particle would have a total $\mathrm{R} / \mathrm{B}$ on the order of $10^{-7}$ for $\mathrm{Kr}-85 \mathrm{~m}, \mathrm{Kr}-87$ and $\mathrm{Kr}-88$ or about 2 orders of magnitude above the current $\mathrm{R} / \mathrm{B}$ values for cycle $140 \mathrm{~B}$.

\section{CONCLUSION}

The AGR-1 Fission Product Monitoring System (FPMS) is a collection of total gamma-ray rate monitors and gammaray spectrometers that are presently monitoring the effluent gases from six individual fuel test capsules under irradiation in the INL's Advanced Test Reactor. It has been key to determining the fuel integrity and performance. Release-tobirth ratios of the detected fission gases have been periodically calculated as a indication of fuel performance. Comparisons between measured $\mathrm{R} / \mathrm{B}$ ratios and predicted $\mathrm{R} / \mathrm{B}$ ratios from semi-empirical models indicate that the $\mathrm{Kr}$ and $\mathrm{Xe}$ fission gas detected by the FPMS is diffusing from uranium contamination in fuel compacts. The FPMS results indicate that the test fuel has surpassed 9\% FIMA burn up with no irradiation-induced TRISO fuel particle failures.

\section{ACKNOWLEDGMENTS}

The authors would like to thank J.T. Maki for many helpful discussions and for providing several key pieces of data. Thanks also to Dr. Ayman Hawari of the North Carolina State University Department of Nuclear Engineering for his guidance in understanding and interpreting the $\mathrm{R} / \mathrm{B}$ models and their application to fuel irradiation experiments. Last but not least we thank the Loop Operation Control (LOC's) personnel at the ATR for their support of the FPMS.

Prepared for the U.S. Department of Energy, Assistant Secretary for Nuclear Energy, Under DOE Idaho Operations Office Contract DE-AC07-99ID13727.

\begin{tabular}{|c|c|c|}
\hline \multicolumn{3}{|c|}{ NOMENCLATURE } \\
\hline AGR & $=$ & Advanced Gas Reactor \\
\hline AIM & $=$ & Acquisition Interface Module \\
\hline ATR & $=$ & Advanced Test Reactor \\
\hline $\mathrm{CPU}$ & $=$ & Central Processing Unit \\
\hline FIMA & $=$ & Fissions per Initial Metal Atom \\
\hline FPMS & $=$ & Fission Product Monitoring System \\
\hline HPGe & $=$ & High Purity Germanium \\
\hline INL & $=$ & Idaho National Laboratory \\
\hline MCA & $=$ & Multi Channel Analyzer \\
\hline MCNP & $=$ & Monte Carlo Neutron and Photon \\
\hline MCS & $=$ & Multi Channel Scalar \\
\hline MCWO & $=$ & Monte Carlo With ORIGEN \\
\hline $\mathrm{NaI}(\mathrm{Tl})$ & $=$ & Thallium doped Sodium Iodide \\
\hline NIST & $=$ & $\begin{array}{l}\text { National Institute of Standards and } \\
\text { Technology }\end{array}$ \\
\hline ORIGEN2 & $=$ & Oak Ridge Isotope Generator 2 \\
\hline PARFUME & $=$ & PARticle FUel ModEl \\
\hline PCGAP & $=$ & $\begin{array}{l}\text { Personal Computer Gamma-Ray } \\
\text { Analysis Program }\end{array}$ \\
\hline $\mathrm{R} / \mathrm{B}$ & $=$ & Release-to-Birth \\
\hline TRISO & $=$ & TRIstructural ISOtropic \\
\hline US DOE & $=$ & $\begin{array}{l}\text { United States Department Of } \\
\text { Energy }\end{array}$ \\
\hline VDM & $=$ & Virtual Data Manager \\
\hline VHTR & $=$ & Very High Temperature Reactor \\
\hline
\end{tabular}

\section{REFERENCES}

[1] Advanced Gas Reactor Team, M. A. Feltus, Program Manager, D. A. Petti, R. R. Hobbins, J. M. Kendall, and J. J. Saurwein, Editors, "Technical Program Plan for the Advanced Gas Reactor Fuel Development and Qualification Program," Idaho National Laboratory, Idaho Falls, ID, Tech. Rep. INL/EXT-05-00465 Rev. 1, Aug. 2005.

[2] J. K. Hartwell, D. M. Scates, and M. W. Drigert, "Design of an On-Line, Multi-Spectrometer Fission Product Monitoring System (FPMS) to Support Advanced Gas Reactor (AGR) Fuel Testing and Qualification in the Advanced Test Reactor," IEEE Trans. on Nuclear Science, 54, No.3,pp.684-689, 2007. 
[3] D. M. Scates, J. K. Hartwell, M. W. Drigert, J. B. Walter, "Preliminary Results of an On-Line, MultiSpectrometer Fission Product Monitoring System to Support Advanced Gas Reactor Fuel Testing and Qualification in the Advanced Test Reactor at the Idaho National Laboratory," Conference Record 2007 IEEE Nuclear Science Symposium/Medical Imaging Conference, Honolulu, HI, Oct. 28 - Nov.3, 2007.

[4] J.T Maki, "AGR-1 Irradiation Experiment Test Plan," Idaho National Laboratory Report INL/EXT05-00593 Rev. 2, March 2007.

[5] S. B. Grover, "Final Assembly and Initial Irradiation of the First Advanced Gas Reactor Fuel Development and Qualification Experiment in the Advanced Test Reactor," Proceedings of ICAPP 2007, Nice, France, May 13-18, 2007, Paper 7305.

[6] D. R. Olander, "Fundamental Aspects of Nuclear Reactor Fuel Elements," Energy Research and Development Administration (ERDA) Technical Document TID-26711-P1, 1976.

[7] D.A. Petti, P. Martin, M. Phelip, R. Ballinger, "Development of Improved Models and Designs for Coated-Particle Gas Reactor Fuels," Idaho National Laboratory Report INEEL/EXT-05-02615, 2004.

[8] J. K. Hartwell, J. B. Walter, D. M. Scates, M. W. Drigert, "Determination Of The AGR-1 Capsule To FPMS Spectrometer Transport Volumes From Leadout Flow Test Data," Idaho National Laboratory Report INL/EXT-07-12494, May 2007.

[9] J. K. Hartwell and S. G. Goodwin, "Pulse injection with subsequent removal: Implementation and applications," IEEE Trans. Nucl. Sci., vol. 36, No. 3, pp. 801-805, Feb. 1989. See also US Patent \#4,968,889 (1990).

[10] E. W. Killian and L. V. East, "PCGAP: Application to analyze gamma-ray pulse-height spectra on a personal computer under Window NTC," J. Radioanalytical Nucl. Chem., Vol. 233, No. 1-2, pp. 109-114, 1998.

[11] E. W. Killian and J. K. Hartwell "PCGAP: Users guide and algorithm description," Idaho National Engineering and Environmental Laboratory Report INEEL/EXT-2000-00908, Sept. 2000.
[12] G. R. Longhurst and L. C. Brown, "Users' Handbook for the Advanced Test Reactor," Idaho National Engineering and Environmental Laboratory Report INEEL/EXT-02-01064, Sept. 2002.

[13] G. Chang, "MCWO - Linking MCNP and ORIGEN2 for Fuel Burnup Analysis," Proceedings of the 2005 ANS Topical Meeting Monte Carlo 2005, Chattanooga, TN, April 17-21, 2005.

[14] D.A. Petti, J. Buongiorno, J.T.Maki, R.R. Hobbins, G.K. Miller, "Key Differences in the Fabrication, Irradiation and High Temperature Accident Testing of US and German TRISO-Coated Particle Fuel, and their Implications on Fuel Performance," Nuclear Engineering and Design, 222 (2003) 281-297.

[15] A. H. Booth, "A Method for Calculating Fission Gas Diffusion from UO2 Fuel and its Application to the X-2-F Loop Test," Atomic Energy of Canada Limited, Report CRDC-721, Atomic Energy of Canada Limited, 1957.

[16] S. Ueta, J. Sumita, K. Emori, M. Takahashi, K. Sawa, "Fuel and Fission Gas Behavior during Rise-toPower Test of the High Temperature Engineering Test Reactor (HTTR)," J. of Nuclear Science and Technology, Vol 40, p. 679-686, 2003.

[17] M. B. Richards, "Fission-Gas Release from UCO Microspheres: A Theoretical Model for Fractional Release from Non-hydrolyzed Fuel with Model Parameters Derived from Capsule HFR-B1 Data," General Atomics Report 818:MBR:001:94, 1994.

[18] J. M. Harp, A. I. Hawari, "Relative Release-to-Birth Indicators for Investigating TRISO Fuel Fission Gas Release Models," Proceedings of PHYSOR 2008 Conference, Interlaken Switzerland, 2008.

[19] J. D. Hunn, F. C. Montgomery, P. J. Pappano, "Data Compilation for AGR-1 Variant 3 Compact Lot LEU01-49T-Z,” ORNL/TM-2006/510 Rev. 0, 2006.

[20] J. T. Maki, Private Communication, 2008.

[21] International Atomic Energy Agency, "Fuel Performance and Fission Product Behavior in Gas Cooled Reactors," IAEA-TECDOC-978, Nov. 1997.

[22] J. M. Harp, A. I. Hawari, "Investigating TRISO Fuel Fission Gas Release Models Using Relative Releaseto-Birth Indicators," Transactions of the American Nuclear Society. Vol. 96, pp. 365-367, 2007. 